Supporting Information

\title{
Electrospun Polyurethane/Zeolitic Imidazolate \\ Framework Nanofibrous Membrane with Superior Stability for filtering performance
}

\begin{abstract}
Haitao Wang, ${ }^{\dagger}$ Huan $\mathrm{Xu},{ }^{\ddagger}$ Han $\mathrm{Li}, \dagger \mathrm{Xiang}$ Liu, ${ }^{\dagger}$ Zhaoqun $\mathrm{Du}^{*}, \dagger$ and Weidong $\mathrm{Yu}^{\dagger}$
$\dagger$ Key Laboratory of Textile Science \& Technology, Ministry of Education, College of Textiles, Donghua University, Shanghai 201620, China

†Engineering Research Center of Technical Textiles, Ministry of Education, College of Textiles, Donghua University, Shanghai 201620, China
\end{abstract}

*Corresponding author:

Email: duzq@dhu.edu.cn 


\section{ZIF}

The crystal structure of ZIF is analogous to zeolites that are built upon 4- connected nets of tetrahedral units where in $\mathrm{Zn}^{2+}$ metal ions is linked through $\mathrm{N}$ atoms in imidazolate anions[1].The crystal structure schematic of ZIF-8 was shown in Figure S1, S2.

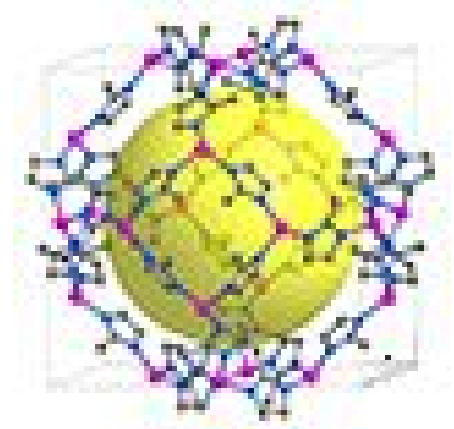

Figure S1. Crystal structure schematic of ZIF-8.
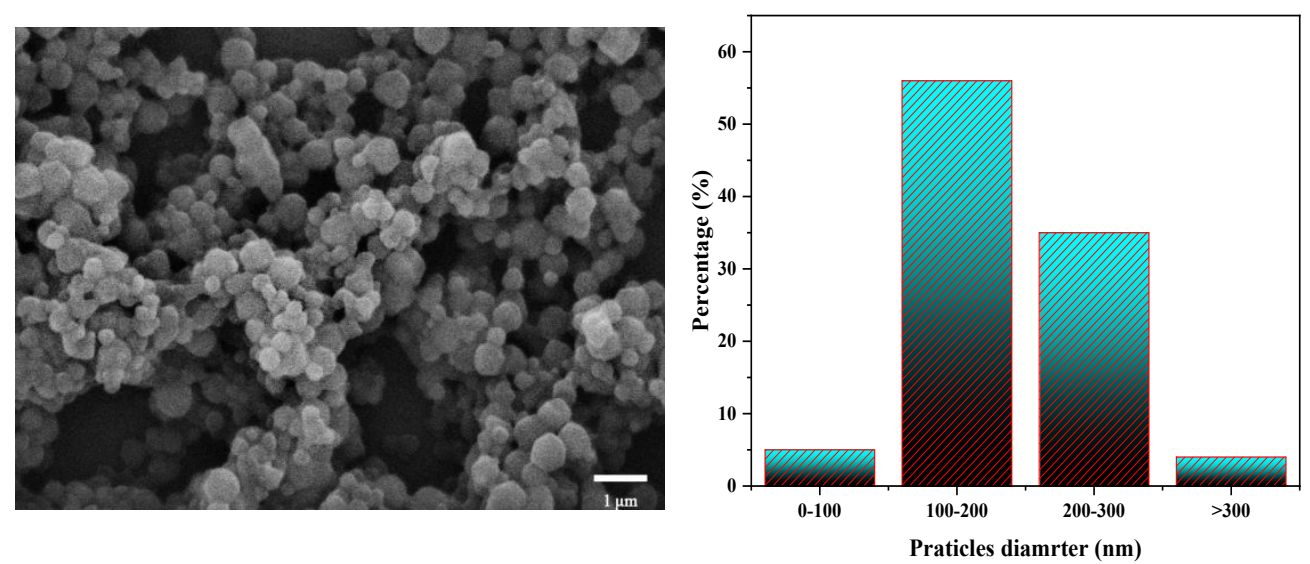

Figure.S2 SEM image of ZIF-8 and its particle diameter distribution. 


\section{$\mathrm{Cr}^{6+}$ standard solution and standard curve drawing}

A certain amount of potassium dichromate (K2Cr2O7) was weighed and dried in an oven at $100{ }^{\circ} \mathrm{C}$ for $3 \mathrm{~h}$,then dissolved in deionized water and stabilized to $1000 \mathrm{~mL}$ and shaken well to obtain a chromium ion reserve solution of $0.1 \mathrm{~g} / \mathrm{L}$.A certain amount of diphenylcarbazide was dissolved in acetone, diluted to $100 \mathrm{~mL}$ with water,placed in a brown bottle for preservation,shaken well and stored in a refrigerator at $4{ }^{\circ} \mathrm{C}$.Add chromium standard solution of different volumes into $50 \mathrm{~mL}$ colorimetric tube,add deionized water and dilute to the marking line,shake well and get chromium ion solution of different concentrations.Add $1 \mathrm{~mL}$ mixed solution of sulfuric acid and phosphoric acid and $2 \mathrm{~mL}$ chromogenic agent,shake well and leave for a period of time and then determine its absorbance at the wavelength of $540 \mathrm{~nm}$. The linear regression equation is $\mathrm{A}=0.6928 \mathrm{C}+0.00272$ and the correlation coefficient is 0.99857 , showing A high degree of correlation.

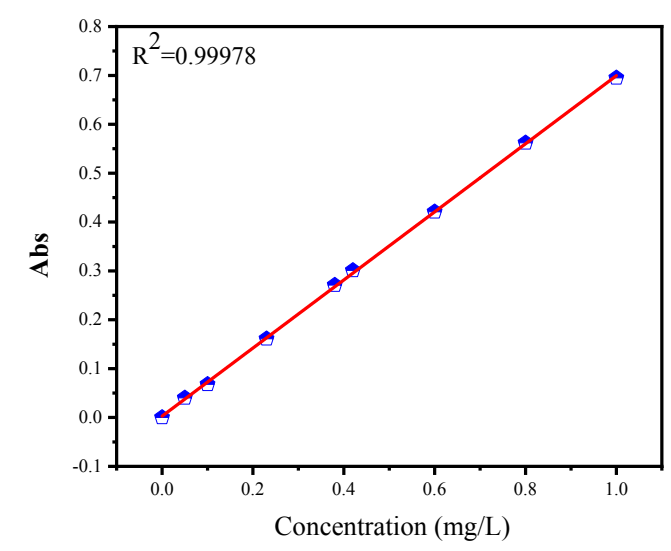

Figure.S3 The relationship between absorbance and concentration 

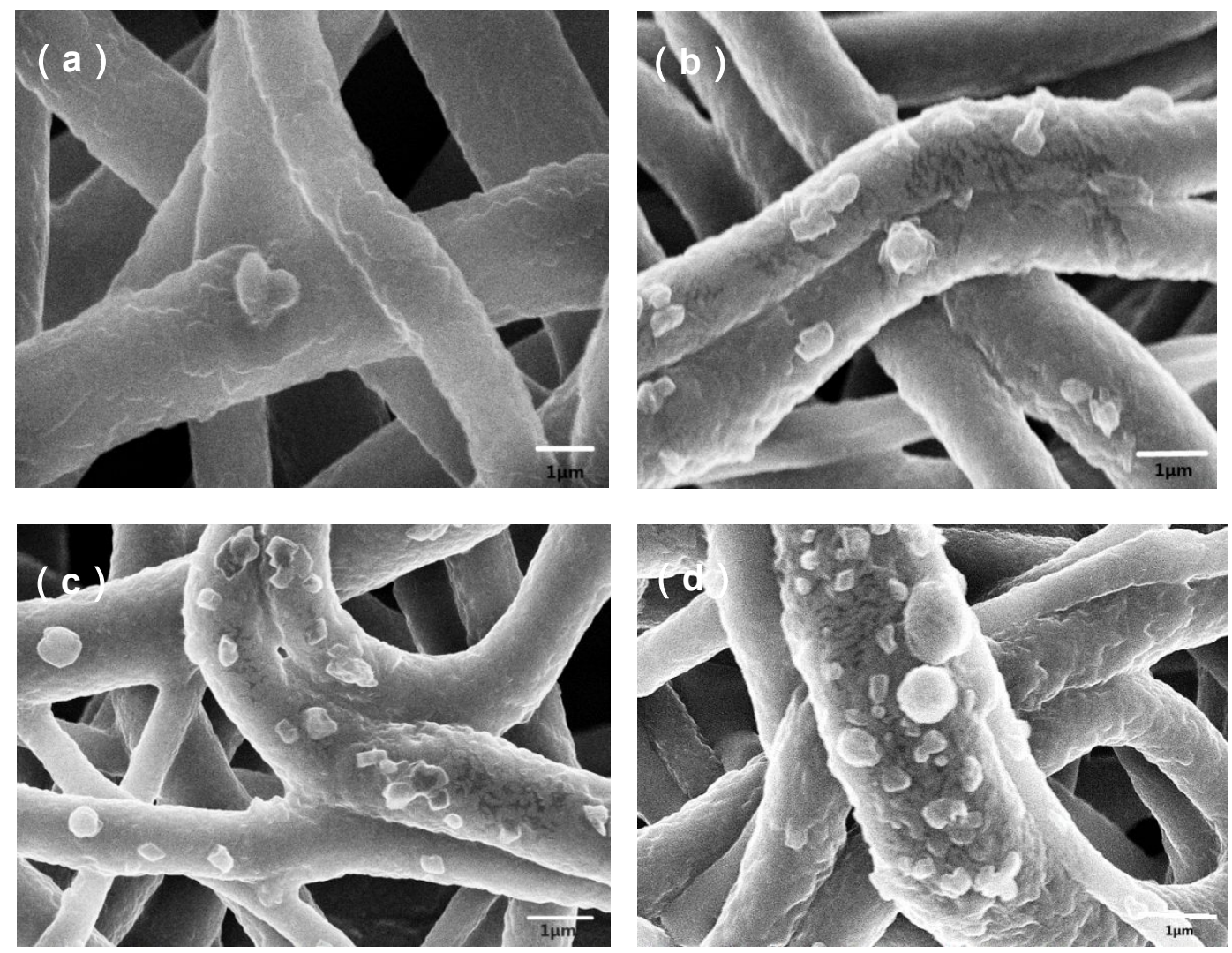

Figure.S4 The SEM of membranes with different ZIF-8 precursor concentrations (a) 5\%,(b) 10\%,(c) $15 \%,(d) 20 \%$.

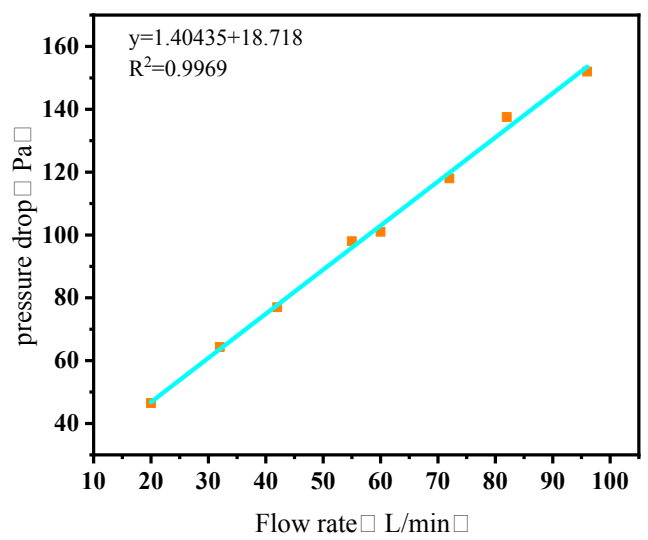

Figure.S5 The pressure drop of PU@ZIF-15 membrane at different airflow rate. 
Table S1.Comparison of $\mathrm{PM}_{2.5}$ filtration performance of PU@ZIF8-15 membrane and other air filters.

\begin{tabular}{|c|c|c|c|c|c|}
\hline Membranes & $\mathbf{P M}(\boldsymbol{\mu} \mathbf{m})$ & $\mathbf{E}(\mathbf{\%})$ & $\boldsymbol{\Delta P}(\mathbf{P a})$ & $\mathbf{Q}\left(\mathbf{P a}^{-\mathbf{1}}\right)$ & $\mathbf{R e f}$ \\
\hline PU@ZIF-15 & DEHC & 99.9 & 105 & 0.0438 & This work \\
\hline PMIA/PSA & PSL & 99.60 & 79 & 0.0699 & $2020[2]$ \\
\hline PAN-10/16 & NaCl & 99.89 & 151.90 & 0.0448 & $2019[3]$ \\
\hline Ag-MOF@CNF@ZIF-8 & DEHC & 94.3 & 157.81 & 0.0182 & $2019[4]$ \\
\hline Ag-MOFs@CNF@CF & DEHS & 91.25 & 122.00 & 0.0200 & $2019[4]$ \\
\hline ZIF-8@CNF@CF & DEHS & 93.75 & 148.00 & 0.0187 & $2019[4]$ \\
\hline PVDF/net & NaCl & 99.99 & 66.70 & 0.1320 & $2018[5]$ \\
\hline
\end{tabular}

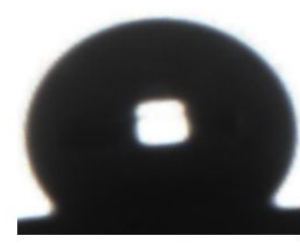

PU@ZIF-5

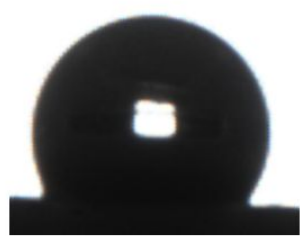

PU@ZIF-15

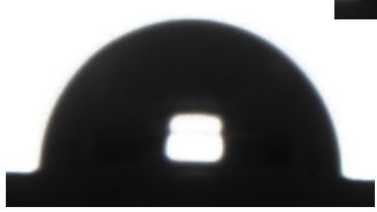

PU

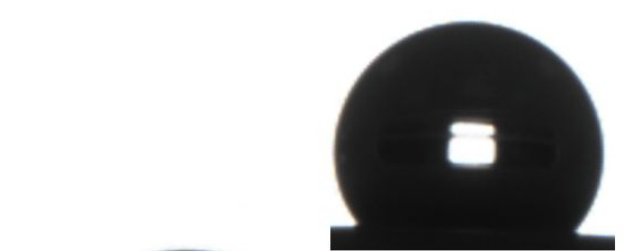

PU@ZIF-10

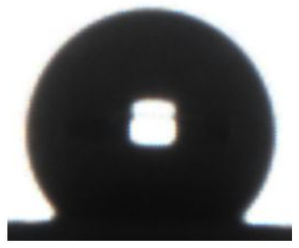

PU@ZIF-20

Figure.S6 Contact Angle of PU with different content of ZIF-8

\section{References}

[1] Hao Z,Wu J,Wang C,et al.Electrospun Polyimide/Metal-Organic Framework Nanofibrous Membrane with Superior Thermal Stability for Efficient PM2.5 Capture[J]. ACS Applied Materials \& Interfaces, 2019,11904-11909. DOI:10.1021/acsami.8b22415 [2] Tian,X.; Zhang, F.; Xin, B.; Liu, Y.; Gao, W; Wang, C.; Zheng, Y. Electrospun MetaAramid/Polysulfone-Amide Nanocomposite Membranes for the Filtration of Industrial Pm2.5 Particles. Nanotechnology 2020, 31 (5), 055702.

[3] Xiong, J.; Zhou, M.; Zhang, H.; Quan, Z.; Wang, R.; Qin, X. Sandwich-Structured Fibrous Membranes with Low Filtration Resistance for Effective Pm2.5 Capture Via One -Step Needleless Electrospinning. Materials Research Express 2018, 6 (3),1-8.

[4] Ma, S.; Zhang, M.; Nie, J.; Tan, J.; Yang, B.; Song, S. Design of Double-Component Metal-Organic Framework Air Filters with Pm2.5 Capture, Gas Adsorption and Antibacterial Capacities. Carbohydr Polym 2019, 203, 415-422.

[5] Li, X.; Wang, C.; Huang, X.; Zhang, T.; Wang, X.; Min, M.; Wang, L.; Huang, H.; Hsiao, B. S. Anionic Surfactant-Triggered 
Steiner Geometrical Poly(Vinylidene Fluoride) Nanofiber/Nanonet Air Filter for Efficient Particulate Matter Removal. ACS Appl Mater Interfaces 2018, 10 (49), 42891-42904. 